\title{
EDITORIAL
}

\section{Genetically engineered lymphocytes and adoptive cell therapy: cancer immunotherapy's smart bombs}

\author{
Cancer Gene Therapy (2015) 22, 63. doi:10.1038/cgt.2015.1
}

Although the concept of cancer immunotherapy, leveraging the power of the body's immune system to fight cancer, is not new, the past few years have seen a surge in the number of positive clinical trials and FDA approvals for new immune-based cancer therapies. Although antitumor vaccines never fully delivered on their promise as stand-alone agents, antibody therapies targeted at immune regulatory 'checkpoints' and genetically modified $T$ cells delivered via adoptive cell transfer have ushered in a new and exciting period of intense bench and clinical research. ${ }^{1-4}$ Impressive clinical results, especially in tumor histologies that have not been classically associated with response to immunotherapy, have been met with a renewed enthusiasm for this approach, yet significant barriers still exist. ${ }^{5-10}$

Challenges such as off-target toxicity for checkpoint inhibitors and large-scale production issues for adoptive cell transfer of genetically engineered $T$ cells present hurdles that must be overcome. These hurdles are the focus of intense efforts in academic laboratories and in the laboratories of major pharmaceutical companies. In this month's issue of Cancer Gene Therapy, the challenges facing widespread application of adoptive cell therapy are addressed by some of the most well-respected experts in this field. Drs Laurence Cooper and Judy Moyes have done a great job as guest editors for this special edition and have brought together six papers that I believe will be seminal contributions.

Translating novel cell-based approaches to the clinic presents unique regulatory challenges. In the paper, 'Manufacturing genetically modified T cells for clinical trials', Dr Adrian Gee takes us through the major points that must be addressed while manufacturing genetically modified T cells for therapeutic use. In 'Manufacture of $T$ cells using the Sleeping Beauty system to enforce expression of a CD19-specific chimeric antigen receptor', Dr Cooper and colleagues outline their approach to nonviral gene transfer using the Sleeping Beauty system and the selective propagation of CD19-specific CAR+ T cells on activating and propagating cells. Dr Cooper also takes us through the process of translation from laboratory-based experiments to the necessary components of commercial manufacture in his paper, 'Moving from tinkering in the garage to assembly line production: the manufacture of genetically modified $T$ cells expressing chimeric antigen receptors (CARs) comes on line'.

The issue is completed with three additional articles that address improvements on current T-cell approaches as well as improvements on manufacturing processes for commercialization. Drs Isabelle Riviere and Xiuyan Wang review the current manufacturing methods for the large-scale production of clinical-grade tumor-infiltrating lymphocytes, virus-specific and genetically modified CAR- or T-cell receptor-transduced T cells in the context of phase I/II clinical trials as well as the regulatory pathway to get these complex personalized cellular products to the clinic in their paper, 'Manufacture of tumor and virus specific T lymphocytes for adoptive cell therapies'. Dr Andrew Kaiser and colleagues take us through their proposal for a decentralized manufacturing model, where in the future, patients' cells could be processed at the point-of-care in the hospital in, 'Towards a commercial process for the manufacture of genetically modified T cells for therapy'. Finally in the paper, 'Performance-enhancing drugs: design and production of redirected chimeric antigen receptor (CAR) T cells', Dr Bruce Levine reviews the steps involved in isolating, genetically modifying and scaling out the CAR T cells for use in a clinical setting and describes this in the context of inprocess and release testing and regulatory standards. It is my hope that the readers of Cancer Gene Therapy will enjoy this special issue.

\section{CONFLICT OF INTEREST}

The author declares no conflict of interest.

SK Libutti

Editor-in-Chief

Cancer Gene Therapy, Bronx, NY, USA

E-mail: editor@cgtnature.com

\section{REFERENCES}

1 Topalian SL, Sznol M, McDermott DF, Kluger HM, Carvajal RD, Sharfman WH et al. Survival, durable tumor remission, and long-term safety in patients with advanced melanoma receiving nivolumab. J Clin Oncol 2014; 32: 1020-1030.

2 Lyford-Pike S, Peng S, Young GD, Taube JM, Westra WH, Akpeng B et al. Evidence for a role of the PD-1:PD-L1 pathway in immune resistance of HPV-associated head and neck squamous cell carcinoma. Cancer Res 2013; 73: 1733-1741.

3 Brahmer JR, Tykodi SS, Chow LQ, Hwu WJ, Topalian SL, Hwu P et al. Safety and activity of anti-PD-L1 antibody in patients with advanced cancer. $N$ Engl J Med 2012; 366: 2455-2465.

4 Topalian SL, Hodi FS, Brahmer JR, Gettinger SN, Smith DC, McDermott DF et al. Safety, activity, and immune correlates of anti-PD-1 antibody in cancer. $N$ Engl J Med 2012; 366: 2443-2454.

5 Watanabe K, Terakura S, Martens AC, van Meerten T, Uchiyama S, Imai M et al. Target antigen density governs the efficacy of anti-CD20-CD28-CD3 $\zeta$ chimeric antigen receptor-modified effector CD8+ T cells. J Immunol 2015; 194: 911-920.

6 Fujiwara $\mathrm{H}$. Adoptive immunotherapy for hematological malignancies using T cells gene-modified to express tumor antigen-specific receptors. Pharmaceuticals (Basel) 2014; 7: 1049-1068.

7 Gill S, June CH. Going viral: chimeric antigen receptor T-cell therapy for hematological malignancies. Immunol Rev 2015; 263: 68-89.

8 Wang Y, Zhang WY, Han QW, Liu Y, Dai HR, Guo YL et al. Effective response and delayed toxicities of refractory advanced diffuse large B-cell lymphoma treated by CD20-directed chimeric antigen receptor-modified T cells. Clin Immunol 2014; 155: $160-175$

9 Magee MS, Snook AE. Challenges to chimeric antigen receptor (CAR)-T cell therapy for cancer. Discov Med 2014; 18: 265-271.

10 Rosenberg SA. Finding suitable targets is the major obstacle to cancer gene therapy. Cancer Gene Ther 2014; 21: 45-47. 